\title{
BREVE HISTORIA DE LA LEXICOGRAFÍA BILINGÜE ESPAÑOLA Y ALEMANA HASTA EL SIGLO XIX
}

\author{
$M^{a}$ José Corvo Sánchez \\ Universidad de Vigo
}

\begin{abstract}
RESUMEN
En este estudio presentamos una breve panorámica del camino trazado por aquellos autores que con sus obras materializaron su quehacer lexicográfico en español y alemán a lo largo de los siglos XVII, XVIII y XIX, convirtiéndose de este modo en los protagonistas de la historia de la lexicografía bilingüe de estas dos lenguas anterior al siglo XX. Esta presentación también pretende ser completa y por ello, junto a los grandes diccionarios, incluye otros repertorios lexicográficos menores, entre los que destaca la obra de Zumaran como primer paso dado en la Historia por esta disciplina.

Palabras clave: historia; lexicografía; bilingüe; español; alemán.

ABSTRACT

This study presents a brief panorama of the roads followed by those authors whose works became proof of their lexicographical endeavours in Spanish and German throughout the 17th, 18th and 19th centuries, thus making them the protagonists of the history of bilingual lexicography of these two languages prior to the 20th century. Aiming at being a complete study, together with the great dictionaries this presentation includes smaller lexicographical inventories. Worthy of note among the latter is Zumaran's work, which constitutes this discipline's first step in History.
\end{abstract}

Keywords: history; lexicography; bilingual; Spanish; German.

\section{INTRODUCCIÓN}

De acuerdo con el estado de la investigación actual, la historia de la lexicografía bilingüe alemana y española comienza en tierras alemanas en el siglo XVII y más concretamente en la ciudad de Viena, donde en 1634 Juan Ángel de Zumaran publica su Nomenclatura española-alemana como parte tercera de su Grammatica y Pronunciación alemana y española. Española y Alemana, el primer Sprachbuch o manual de lenguas bilingüe conocido en la Historia.

Los siglos precedentes $-\mathrm{y}$ fundamentalmente a partir de la segunda mitad del siglo XVconstituyeron un periodo muy productivo para la lexicografía europea, que en esos años se nos presenta rica en obras plurilingües y en forma de compendios de vocabulario eminentemente prácticos, destinados a viajeros y comerciantes principalmente, que son fiel 
reflejo de la necesidad cotidiana de traducir existente en este momento para satisfacer las exigencias de un público cada vez más variado: en las escuelas, la iglesia, la corte, las notarías, los puertos, las embajadas o en las representaciones diplomáticas.

En este conjunto de obras plurilingües se encuentran los primeros pasos dados por determinados pares de lenguas en la historia de la lexicografía europea, como es el caso de las que nos ocupan, la alemana y la española, las cuales comienzan a coincidir en el siglo XVI formando parte de diferentes compendios de vocabulario multilingües.

El final del siglo XVII está protagonizado por Nicolas Mez de Braidenbach, autor del primer diccionario bilingüe español-alemán conocido y con el que Mez representa el paso de la nomenclatura o Namensbuch al diccionario o Wörterbuch en la historia de la lexicografía bilingüe de estas dos lenguas, que será continuado en el siglo siguiente con la publicación de otras nomenclaturas, vocabularios o Wörterverzechnisse y de los primeros Handwörterbücher o diccionarios manuales español-alemán.

La llegada del año 1800 supone algo más que el paso de un siglo a otro en la historia de la lexicografía bilingüe de estas lenguas, pues es el comienzo de una nueva etapa que arranca con su primer gran diccionario bilingüe, el Nuevo diccionario español/alemán y alemán/español de Johann Daniel Wagener, continúa con la aparición de los Taschenwörterbücher o diccionarios de bolsillo y culmina con el gran diccionario de Tolhausen, en cuyo segundo tomo, publicado en 1889, encontramos por primera vez un diccionario alemán-español con una entidad comparable a la más frecuente hasta entonces en la historia de la lexicografía de este par de lenguas, la de español-alemán.

Los siglos XX y XXI configuran una época muy diferente a las anteriores en la historia de la lexicografía de las lenguas española y alemana tanto por la cantidad, como por la variada naturaleza de las obras lexicográficas que se publican. Este tramo de la historia que nos ocupa bien pudiera ser objeto de estudio en el futuro, pero no tiene cabida en el presente trabajo, en el que, como se desprende de su título, nos ocupamos del pasado de esta disciplina anterior al siglo XX.

El fin último de este estudio pretende ser una modesta contribución a la historia de la lexicografía bilingüe europea de las lenguas alemana y española hasta el siglo XIX y para ello nos detendremos en conocer la evolución y la diversidad de materiales confeccionados como inventarios léxicos a lo largo de más de tres siglos, así como los nombres de quienes los idearon, protagonizando de este modo la historia de esta disciplina.

De tal modo que en las páginas siguientes presentamos lo que podríamos denominar un inventario de inventarios léxicos en español y alemán en orden cronológico de aparición, lo que nos llevará, en primer lugar, a conocer los primeros pasos dados por las lenguas española y alemana en el conjunto de la producción lexicográfica plurilingüe europea del siglo XVI y más concretamente en aquellos primeros vocabularios multilingües en los que éstas aparecieron juntas y que constituyen los antecedentes de la nomenclatura bilingüe que Juan Ángel de Zumaran incluye en su manual de lenguas de 1634 y del diccionario de 1670 de Mez de Braidenbach. Y sólo después daremos cuenta de los compendios de vocabulario de los que tenemos noticia aparecidos en los diferentes contextos de los siglos posteriores, cumpliendo nuestro objetivo de trazar una breve historia de la lexicografía bilingüe de las 
lenguas española y alemana, a través de una panorámica de las obras y del quehacer lexicográfico desde los comienzos y hasta llegar a las puertas del siglo XX.

Cierto es que un estudio riguroso de esta naturaleza, además de abarcar el inventario y la descripción de todas las obras bilingües de tipo lexicográfico conocidas, debería explorar en detalle las circunstancias y las causas que hicieron posible su aparición, además de ocuparse del análisis del léxico contenido en ellas en ambas lenguas y de la localización de sus fuentes. En el marco de este trabajo, sin embargo, esto no es posible y en general nos limitaremos a exponer brevemente ciertos datos que consideramos de interés para la mejor comprensión de la tipología y de las circunstancias que favorecieron su aparición.

Junto a los diccionarios, en esta exposición nuestro interés también se centra en presentar otros repertorios de vocabulario que resultan menos conocidos y que hasta ahora han quedado excluidos de este tipo de estudios. Nos referimos a los compendios de vocabulario que se hallan en la línea de la nomenclatura de Juan Ángel de Zumaran: son registros temáticos de vocabulario en su mayoría que se encuentran insertados dentro de otras obras que suelen llevar el título de "gramática", cuando en realidad este término hace referencia a un método o manual de lenguas más completo.

De este modo pretendemos que nuestra contribución al conocimiento de la historia de esta disciplina complete otros trabajos publicados sobre el tema ${ }^{1}$. Y para que esta contribución resulte aún más valiosa, en la sección dedicada al siglo XVII de forma excepcional centramos nuestra atención en el estudio de la citada nomenclatura de Juan Ángel de Zumaran. Además de ser el primer testimonio conocido de este otro tipo de compendios lexicográficos que acabamos de referir, representa un hito en la historia de la lexicografía bilingüe europea de este par de lenguas por ser el primer compendio de vocabulario bilingüe español-alemán conocido y con este trabajo queremos resaltar la relevancia de este hecho.

\section{LOS COMIENZOS DE LA LEXICOGRAFÍA ESPAÑOLA Y ALEMANA: SIGLO XVII}

\subsection{Los primeros pasos: vocabularios multilingües}

Si bien el intercambio cultural hispano-alemán comienza ya a finales del siglo XIV, lo cierto es que la relación entre hablantes de castellano y de alemán se intensifica a partir del siglo XV y se estrecha aún más en el siglo siguiente tras la muerte de Maximiliano I en 1519, cuando su nieto Carlos I, rey de España, sube al trono alemán con el nombre de Carlos V; poco después, la subida al trono en Austria de su hermano como Fernando de Habsburgo, en 1522, vendría a consolidar nuevos lazos culturales, además de los

\footnotetext{
${ }^{1}$ Como son, por ejemplo, los de 1956-1957 y 1958 de Schlipf, quien se ocupa de los diccionarios en español y alemán a partir del de Schmid de 1795; los de Haensch y Fuentes de 1991 y de 2000, respectivamente, que ofrecen una panorámica global desde el diccionario de Mez de 1670 hasta el siglo XX; y el de 1992 de Marín, quien sólo se ocupa parcialmente del tema e igualmente comienza su relato histórico a partir de diccionario de Mez.
} 
meramente políticos y económicos, entre la Corona española y los países de habla germánica.

Bajo la corona de Carlos I de España y V de Alemania Europa se convirtió en un espacio multilingüe y multicultural obligado a entenderse, ya que se unificaron por primera vez en la Historia territorios muy diferentes, como España, Nápoles, Sicilia, Cerdeña, el Franco-Condado, el Ducado de Milán, los Países Bajos y Austria, que formaban los territorios patrimoniales de los Habsburgo, además del Sacro Imperio Románico Germánico.

Fue éste un tiempo en el que muchos alemanes, artistas, artesanos y otros muchos en busca de fortuna, se relacionaron con España, afincándose en este país o pasando por él atraídos por los descubrimientos del Nuevo Mundo. Como resultado de todo ello, en España se crearon diversas colonias de alemanes en diferentes puntos de su territorio: en el entorno de la minas de Almadén, donde llegaron muchos mineros alemanes para trabajar y aplicar sus conocimientos, ya que la técnica minera se hallaba mucho más desarrollada en Centroeuropa; en Sevilla, puerta del comercio de ultramar; en la Corona de Aragón, en donde se instalaron muchos mercaderes alemanes; o en Barcelona y Valencia, hasta donde llegaron principalmente comerciantes e impresores alemanes para introducir su oficio en estas tierras ${ }^{2}$.

La repercusión principal en el ámbito lingüístico de estos asentamientos la constituye el Vocabolari molt profitos per apendre Lo Catalan Alamany y Lo Alamany Catalan que a partir de otro vocabulario anterior italiano-catalán publicó en Perpiñán el impresor Rosenbach en 1502 y que ya testimonia la necesidad de aprender esta lengua por parte de los comerciantes alemanes del sur de Alemania establecidos desde finales del siglo XIV en Barcelona.

Resulta interesante por ser la primera recopilación de vocabulario conocida que incluye el alemán con una lengua española y más aún si tenemos en cuenta que su traductor, que no debió ser un hombre de letras, presenta una traducción cargada de barbarismos por influencia de la lengua castellana (Rubió 1962: 120; Neumann-Holzschuh 1991: 257, 275).

En este momento de prosperidad política y cultural, los españoles no necesitaban aprender otras lenguas porque, además, el español "estaba de moda" y se aprendía en las cortes de otros países. Así lo testimonian las siguientes palabras que Villalón dejó escritas en el "Prohemio al lector" de su Gramática, explicando las razones que le llevaron a redactarla:

[...] porque la pudiessen todas las naçiones aprender [...] Tambien me mouio a este trabajo ver que estamos en edad que es necesario pues vemos que se preçisa en todas las naciones muy sabios varones escreuir en sus lenguas muy vulgares y ansi lo vsan varones Castellanos muy eminentes en elegâte estilo Latino escreuir: forçanse por el consiguiente a esta empresa ver el comun de todas las gentes inclinadas a esta dichosa lengua y que les

\footnotetext{
${ }^{2}$ Éstos últimos crearon la cofradía Santa Bárbara del Alemanys para atender las necesidades de los inmigrantes germanos, unidos por su lengua y su cultura; en Valencia se fundó el Convento Vall de Jesús y la compañía comercial creada por los Fugger, la Grosse Ravensburger Gesellschaft, fundó un hospital.
} 
aplaze mucho y se preçian de hablar en ella. El Flamenco, el Italiano, Ingles, Françes. Y avn en Alemania se huelgan de la hablar: avnque se presume que sea alguna parte de causa ver que el nuestro Emperador Carlos se preçia de Español natural. Que ansi vimos, que al tiempo que su magestad vençio la batalla a Lansgraue y al Duque de Saxonia junto al rio Albis, vinieron todas las Señorias y prinçipados de Alemania a se le subietar y obedeçer: y a demâdar le perdô. Y todos le hablauân en español: avn que pareçe que era algo por le complacer ${ }^{3}$.

En Alemania, como vemos, "se huelgan en la hablar"; sin embargo, no contaban con ninguna obra gramatical publicada en tierras alemanas con la que aprender el castellano, por lo que debemos creer que, como lo hicieron los comerciantes, los viajeros y los diplomáticos de toda Europa, para su estudio se sirvieron básicamente de los vocabularios y de las colecciones de diálogos que, conteniendo la lengua española, pudieran tener a su alcance.

Una visión panorámica de estos compendios léxicos publicados con el español, tanto dentro como fuera del territorio de habla alemana, nos llevaría a referir una cantidad innumerable de vocabularios plurilingües de los que no podemos ocuparnos en este trabajo; no obstante, para los fines de este estudio es interesante que nos detengamos a conocer algunos de ellos y de forma particular aquellos casos donde hallamos los primeros pasos de la lexicografía en alemán y español.

De acuerdo con Haensch ${ }^{4}$, las lenguas alemana y española aparecen reunidas por primera vez a principios del siglo XVI en el Dictionarium sex linguarum Latinae, Gallicae, Hispanicae, Italicae, Anglicae et Teutonicae dilucidissimum, publicado en Zúrich en $1505^{5}$.

Un caso temprano lo constituyen también las ediciones en cinco lenguas del Introito $e$ porta $^{6}$ y que junto al español y al alemán incluyen también el latín, el francés y el italiano. La primera conocida apareció en Venecia en 1513 (Palau, VII: 219). A continuación recogemos el título de la segunda, aparecida en la misma ciudad en el año 1526 y con el siguiente título:

Quinq; linguarum vtilissi/mus Vocabulista / Latine Tusche Gallice Hyspa/ne et Alemanice. Valde ne/cessarius perm mun/dum versari / cupienti/bus.// Nouiter per Franciscum Garonum maxima / diligencia in lucem elaboratus.// Vocabulista de le cinque lengue. Cioes Latina / Toscaza, Franzosa, Spagnola, et Tudesca// ${ }^{7}$

\footnotetext{
${ }^{3}$ Citamos a través de Viñaza (1893: 244).

${ }^{4}$ Remitimos a las páginas 2910, 2913 y 2927 de su trabajo de 1991, que resulta muy interesante, además, para obtener una panorámica general de la naturaleza y tipología de los repertorios lexicográficos plurilingües, y fundamentalmente multilingües, más antiguos de Europa.

${ }^{5}$ Otros autores citan fechas diferentes para esta obra: véase, por ejemplo, Niederehe (1994: 438).

${ }^{6} \mathrm{El}$ Introito e porta de quele que voleno imparare e comprender todescho a latino, cioe italiano es una nomenclatura y constituye la más temprana recopilación de léxico bilingüe en lenguas modernas conocida. Apareció anónimamente en Venecia en 1477 en la imprenta del maestro Adamo de Rodauila o Rottweil y recoge a dos columnas las correspondencias en italiano septentrional y en alemán.

${ }^{7}$ Citamos a través de (Gallina 1959: 31). Esta autora recoge en la página 39 de su estudio las ediciones del Introito conocidas en cinco lenguas.
} 
$\mathrm{Y}$ un caso curioso de coincidencia de las lenguas que nos ocupan en una obra multilingüe lo constituye el vocabulario incluido en la edición de Amberes de 1552 de la obra Exercitatio linguae latinae de Vives, tal como reflejan las siguientes palabras de Breva sobre las diferentes ediciones de esta obra:

[...] en 1539 esta obra salió a la luz en París y en Basilea con un mismo título Linguae Latinae exercitatio. Libellus valde doctus \& elegans, nuncque primum in lucem editus [...] Hacia 1544, comenzaron a aparecer las ediciones con notas de Pedro Mota, un discípulo de Nebrija, para explicar palabras y frases oscuras, y un índice latino-hispano de voces difíciles, compilado por un tal Juan Ramírez. El número de anotaciones, comentarios y traducciones en las distintas lenguas europeas creció rápidamente a medida que aumentaba la popularidad de los Diálogos. En la edición de Amberes de 1552, encontramos un vocabulario trilingüe en francés, alemán y español. En la edición de Florencia de 1568, dicho vocabulario aparece en italiano [...] Fue traducido al francés, italiano, español, alemán, polaco, inglés y catalán, siendo impreso muchas veces en versiones bilingües para facilitar el aprendizaje del latín a través de la traducción. (1994: 24-5)

Lo cierto es que en el siglo XVI proliferaron los compendios multilingües con los títulos más diversos: Thesaurus, Lexicon, Vocabulista, Vocabularium, Dictionarium, etc. (Haensch 1991: 2912). Algunos de ellos son ediciones multilingües concebidas como tales; otros, en cambio, son versiones de anteriores ediciones bilingües conteniendo un número mayor de lenguas.

Estos vocabularios fueron elaborados como auxilios lingüísticos muy prácticos y en su conjunto respondían a una organización del vocabulario temática o alfabética -entendiendo como tal un orden alfabético aproximativo-. En su gran mayoría consistían en listas de nombres que en sus hojas precedentes podían incluir tanto reglas de pronunciación, como un breve compendio gramatical básico centrado fundamentalmente en la morfología de las palabras y en la conjugación de los verbos, así como también una pequeña colección de diálogos para facilitar a los estudiantes el aprendizaje de la lengua extranjera de un manera viva, además de otros elementos, como colecciones de refranes, tratados fraseológicos, etc. (Corvo 2007: 41).

Las recopilaciones de vocabulario bilingües igualmente tienen un carácter práctico y claramente didáctico y, como las multilingües, su demanda también parece justificada desde muy pronto en Europa, donde ya con anterioridad al siglo XV el conocimiento de idiomas socialmente implicaba un signo de poder.

$\mathrm{Y}$ así es una realidad que los primeros compendios de vocabulario bilingües vernáculavernácula conocidos comenzaron a publicarse en la segunda mitad del siglo XV, recogiendo las combinaciones de las lenguas más importantes probablemente de determinadas zonas, como el italiano y el catalán -junto con el griego- en el espacio comercial mediterráneo o el alemán como la lengua dirigente en las relaciones comerciales entre las ciudades del sur de Alemania e Italia.

De hecho, el primer vocabulario bilingüe conocido de dos lenguas modernas es el Introito e porta de quele que voleno imparare e comprender todescho a latino, cioe italiano, al que ya nos hemos referido con anterioridad. Esta nomenclatura constituye un 
ejemplo especialmente interesante porque se convirtió en modelo del quehacer lexicográfico de la época ${ }^{8}$. Ya en los últimos años de la Edad Media los comerciantes alemanes habían creado en Venecia la asociación de comerciantes alemanes Fondaco dei Tedeschi y esta pequeña obra, como testimonio escrito de que los italianos se vieron obligados a aprender alemán para negociar con ellos, también da fe de la prosperidad económica alemana en los últimos años de la Edad Media.

Junto a esta temprana recopilación de vocabulario bilingüe con el alemán, también es posible encontrar otras con el español y otras lenguas'; no obstante, en lo que a la combinación concreta de las lenguas española y alemana se refiere, lo cierto es que resulta tardía y poco frecuente, pues hay que esperar hasta el siglo XVII para encontrarlas por primera vez y tan sólo en las dos obras siguientes: la Nomenclatura de 1634 de Juan Ángel de Zumaran y el Diccionario muy copioso de la lengua española y alemana de Nicolas Mez de Braidenbach de 1670.

\subsection{Los primeros testimonios bilingües en español y alemán: Juan Ángel de Zumaran y Mez de Braidenbach}

Juan Ángel de Zumaran fue un español afincado en tierras alemanas, donde trabajó como maestro de lenguas en las ciudades de Múnich, Ingolstadt y Viena en las primeras décadas del siglo XVII. Y Mez de Braidenbach fue un maestro de artes y notario de la Viena de la segunda mitad del siglo XVII ${ }^{10}$.

Uno y otro nos interesan de manera especial, pues sus nombres son realmente los de los primeros protagonistas en el relato que nos ocupa sobre la historia de la lexicografía bilingüe de las lenguas españolas y alemana, ya que en el conjunto de sus obras encontramos los dos primeros grandes hitos de esta disciplina, como avanzábamos en las páginas iniciales.

Juan Ángel de Zumaran es autor de los siguientes cuatro Sprachbücher o libros de lenguas: el Tyrocinium de 1617 en tres lenguas, Das Newe Sprachbuch de 1621 en cuatro lenguas, el Thesaurus de 1626 en cinco lenguas y la Grammatica y Pronunciación alemana y española. Española y Alemana de $1634^{11}$. Estos manuales forman un conjunto en el que encontramos gramática -pronunciación y tipos de palabras, básicamente-, diálogos,

\footnotetext{
${ }^{8}$ Remitimos al trabajo de Gallina (1959) y en concreto a las páginas 28-29, donde la autora recoge el conjunto completo de temas que incluye esta obra.

${ }^{9}$ Puede consultarse el trabajo de Niederehe de 1994, una de las más recientes recopilaciones bibliográficas de todas las obras relacionadas con el español que fueron impresas en el siglo XVI con las que contamos en la actualidad. Muy ilustrativa resulta también la lectura de la parte segunda dedicada a la lexicografía bilingüe de la edición de Ahumada de 2000.

${ }^{10}$ Remitimos a Corvo (2007a) para saber más sobre la vida y obra de Zumaran. Sobre la biografía de Mez von Braidenbach tan sólo se conoce su título y profesión, "maestro en Artes y Notario Cesareo Publico", tal como reza el título de su Gramatica de 1666.

${ }^{11}$ Los títulos completos de estos libros, así como las diferentes ediciones de los mismos conocidas pueden consultarse en Corvo (2007a: 145-146).
} 
nomenclaturas, refranes, dos tratados fraseológicos, oraciones religiosas y un catálogo con el nombre de las principales universidades europeas.

Las nomenclaturas son registros temáticos de nombres que Juan Ángel de Zumaran presenta en capítulos configurados en torno al vocabulario básico y necesario para el desempeño de las diferentes actividades que gobernaban la vida cotidiana de los hombres de su época; las diferencias más resaltables que podemos reseñar entre todas las contenidas en el conjunto formado por sus libros de lenguas atañen básicamente al número y disposición de las lenguas tratadas en cada obra, como esquemáticamente mostramos a continuación:

\begin{tabular}{|c|c|c|c|c|}
\hline $\begin{array}{l}\text { Libros de lenguas } \\
\rightarrow\end{array}$ & Tyrocinium 1617 & Sprachbuch 1621 & Thesaurus 1626 & $\begin{array}{c}\text { Grammatica } \\
1634\end{array}$ \\
\hline $\begin{array}{l}\text { Número de lenguas } \\
\text { // disposición } \\
\rightarrow\end{array}$ & $\begin{array}{c}3 / / \\
\text { en } 1 \text { pág. y en } \\
\text { línea: italiano, } \\
\text { francés y alemán }\end{array}$ & $\begin{array}{c}4 \text { // } \\
\text { en } 2 \text { pp. y } 4 \\
\text { columnas: } \\
\text { francés-italiano y } \\
\text { español-alemán }\end{array}$ & $\begin{array}{c}5 / / \\
\text { en } 2 \text { pp. y } 5 \\
\text { columnas: latín- } \\
\text { italiano-francés } \\
\text { y esp.-alemán }\end{array}$ & $\begin{array}{c}2 \text { // } \\
\text { en } 1 \text { pág. y } 2 \\
\text { columnas: } \\
\text { español-alemán }\end{array}$ \\
\hline
\end{tabular}

Concebidas todas ellas bajo este mismo criterio y con idéntica pretensión, presentan una configuración muy similar, pues son versiones revisadas y corregidas de la primera, la del Tyrocinio de 1617. En el siguiente apartado nos centraremos en la nomenclatura bilingüe de la Grammatica de 1634, lo que nos servirá también para iltustrar el quehacer lexicográfico de Zumaran; antes de ello, no obstante, nos detendremos brevemente en conocer la labor lexicográfica de Nicolas Mez de Braidenbach.

Su aportación a la historia de la lexicografía bilingüe española y alemana la constituye su Diccionario muy copioso de la lengua Española y Alemana, publicado en Viena en 1670 y dedicado expresamente al Emperador Leopoldo $\mathrm{I}^{12}$. Y, si bien sólo presenta la combinación de lenguas español-alemán, representa el paso de la nomenclatura o Namensbuch al Wörterbuch o diccionario, es decir, del repertorio de nombres organizado temáticamente al libro diccionario ordenado alfabéticamente $\mathrm{y}$, con ello, protagoniza de modo especial la historia de la lexicografía bilingüe de este par de lenguas por ser el primer diccionario bilingüe conocido de ambas.

Mez también es autor de dos gramáticas publicadas igualmente en Viena: Fontaine de la Langue Françoise de 1661 y Gramatica, o Instruccion española, y alemana de 1666. La primera es una gramática de la lengua francesa para hablantes de alemán y la segunda es un breve manual que recoge un apartado sobre la pronunciación de la lengua española redactado para hablantes de alemán, así como otros apartados monolingües, en español o en alemán, y otras partes dedicadas al verbo, al adverbio, etc. que también incluyen la lengua

\footnotetext{
${ }^{12}$ Más información sobre esta obra puede consultarse en Hausmann (1984) y Messner (1999).
} 
italiana. Su título en alemán, aunque resulta igualmente impreciso, detalla el número de lenguas manejadas en la obra: Grammatica, Oder Unterweisung der Spanischen Teutschen und Welschen Sprach.

La obra de Mez, como decimos, se sitúa en la Viena de la segunda mitad de siglo y en un momento en el que el interés por el español se halla respaldado por cierto acontecimiento histórico: la boda del Emperador Leopoldo I con su sobrina la Infanta española Maria Teresa, hija de Felipe IV y de la archiduquesa Mariana, hermana de Leopoldo I en 1667.

Posiblemente este fue el motivo que originó que dos años antes también viera la luz en Viena una nueva edición del Thesaurus de 1626 de Juan Ángel de Zumaran que, sin embargo, fue publicada anónimamente (Corvo 2007a: 53). La publicación de estas obras, en definitiva, sirve de testimonio de un momento histórico en el que la Corte de Viena se había convertido en el centro de la cultura y de la influencia españolas en Europa central y desde donde también se llegaba a otras cortes alemanas y principalmente a la de Baviera. Entre otras cosas, esto explica que en el siglo XVII muchos príncipes alemanes dominaran el español y que esta lengua se introdujera también como extranjera en otros centros formativos, como sucedió a partir de 1650 en las universidades de Gießen y de Helmstedt o en la Ritterakademie o academia de caballeros de Wolfenbüttel a partir de 1687 (Dahmen 1991: 258).

\subsection{La nomenclatura bilingüe de Juan Ángel de Zumaran}

Se presenta en la página 439 de la Grammatica de 1634 con el siguiente título:

Nomenclatura muy cumplida de todos los vocablos mas necessarios, que ocurren y son menester para la comunicación cotidiana. Devidida en 31. capitulos cuyos contenidos se puede veer por la tabla siguiente. Reuista y corregida Por Iuan Angel de Zumaran. Año 1634. (p. 439) ${ }^{13}$

Los 31 capítulos que la componen están elaborados en torno a los siguientes temas:

(1) De las junturas, miembros, y partes del hombre. (pp. 350-358)

(2) De las virtudes de los hombres. (pp. 358-360)

(3) De los vitios del hombre. (pp. 360-364)

(4) De los vestidos y sus espicies. (pp. 364-368)

(5) De las Materias con las quales se hazen los vestidos. (pp. 369-371)

(6) De las cosas tocantes à vna casa dentro y fuera. (pp. 371-376)

(7) De las Dignidades y officios de los Ecclesiasticos. (pp.376-378)

\footnotetext{
${ }^{13}$ Seguido en la misma página por su versión alemana: "Das dritte Theyl. Ein Volkomenliche Nomenclatur aller nothwendigisten Wórtern / die zu der táglichen Communication von nóthen seynd. In 31. Capitlen außgethailt / deren Inhalt man durch den nachvolgenden Register ersehen kan. Von newem vbersehen vnd corrigiert. Durch Joannem Angelum von Sumaran. Anno 1634”.
} 
(8) De los officios y dignidades temporales. (pp. 379-384)

(9) De los edificios y sus partes. (pp. 384-386)

(10) De los edificios Ecclesiasticos y escolasticos, con sus partes. (pp. 386-387)

(11) Edificios Politicos y militares con sus pertinencias y propriedades. (pp. 388389)

(12) Los nombres de las armas y cosas tocantes à la guerra. (pp. 389-393)

(13) De los libros, escrituras y nombres de las cosas à ello tocantes. (pp. 394397)

(14) De los Instrumentos y cosas musicales. (pp. 397-399)

(15) De los Cauallos carros, y cosas tocantes à ellos. (pp. 399-404)

(16) De los Animales quadrupedes, assi domesticos como saluajes. (pp. 405-408)

(17) De los nombres de pajaros. (pp. 408-410)

(18) De los nombres de los pescados. (pp. 411-412)

(19) De otras suertes de gusanos, moscas, y bestias ponçoñosas. (pp. 412-413)

(20) Vn appendis del sobredicho capitulo, donde se declaran las partes y frutos de los animales. (pp. 414-417)

(21) De vn casamiento, y de todo lo que à vn casamiento conuiene. (pp. 417-419)

(22) De los parientes y amigos. (pp. 419-422)

(23) De los nombres de artes mecanicas, y otras professiones. (pp. 422-426)

(24) De vn Iardin con todo lo que en el ha de hauer. (pp. 427-441)

(25) De todo genero de especias (pp. 431-432).

(26) De todas suertes de lengumbres y granos. (pp. 433-434)

(27) Para aprender à contar. (pp. 434-440)

(28) De las colores. (pp. 441-442)

(29) Del tiempo, edad fiestas del año, y dias de la semana, con sus lugares nonbres y circunstancias. (pp. 442-448)

(30) De las Monedas y sus partes. (pp. 448-450)

(31) De diuersos generos de juegos. (pp. 451-452)

Es una nomenclatura española con sus correspondencias en alemán dispuesta en dos columnas, tal como ilustramos a través de los siguientes términos del último de estos capítulos mencionados: 


Hispanica
Tablero de àxedrez
naypes
vna dança, vn baile

\author{
Germanica \\ Ein Schachspiel \\ ein Kartenspiel \\ ein Tanz ... (p. 451)
}

En cuanto al léxico de esta nomenclatura, frente al correcto castellano, el alemán no está exento de errores y presenta regionalismos y variantes dialectales -como Stiege, Beck, Körble, Jenner, etc.- que denotan el dominio del alemán del sur o Oberdeutsch de su autor (Dahmen 1991: 265).

Y respecto a su procedencia, coincidimos con Gallina (1959: 292) al creer que en general se trata de una elección y de una traducción personal del vocabulario por parte de Zumaran, lo que le permite conseguir un resultado original, a pesar de parecerse al recogido en otras obras existentes, como el famoso anónimo Introito a porta.

Más en detalle, además, sabemos que Zumaran conocía y manejaba las obras de Levinus Hulsius y de Girolamo Vittori, de las que debió documentarse y en las que muy posiblemente podremos encontrar claras influencias en próximos estudios. De momento, lo que podemos aportar aquí son las propias palabras de Zumaran, expresadas en el texto preliminar dirigido al lector de su Tyrocinium de 1617, aconsejándole el uso de los diccionarios de estos autores para aprender a componer:

Die Dietionaria so du neben diser Grãmatica lernen zu componirn solst haben/ sollen sein in der Frantzósischen sprach Dictionarium Leuini Hulsii. Frantzósich vnd Teutsch/ Teutsch ṽ̃ frantzósisch/ vnd fúr die jenigen so nicht Teutsch kinnen/ den Dictionarium

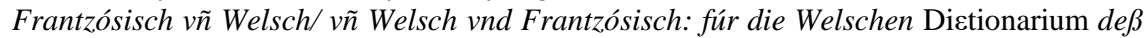
besagten Autoris, Welsch vnd Teutsch/ Teutsch vnnd Welsch: Da aber einer alle drey sprachen beysammen wolt haben/ neme er den Distionarium eiusdem Autoris Leuini Hulsii, so 1616. ist getruckt worden/ in welchem er alle drey Sprachen beysammen hat/ Frantzósisch Welsch vnd Teutsch/ Welsch Frantzósisch vnd Teutsch/ Teutsch Frantzósisch vñ Welsch/ guet/ correct vnd nutzlich. Da aber einer dise drey sprachen kan/ un wolte lernen Spanisch/ der neme den Diktionarium, intitulirt, Tesero de tres lenguas, getruckt zu Genff in Franckreich/ $v \tilde{n}$ die andern zu Franckfurt [...]. $\left(8^{\mathrm{v}-} 9^{\mathrm{r}}\right)^{14}$

Zumaran representa toda una época en la historia de la lexicografía bilingüe española y alemana: la primera, iniciada un siglo antes y protagonizada por el frecuente contacto de hablantes de estas lenguas, como resultado de una España con representación en los diferentes territorios alemanes, y por la demanda de la traducción y la interpretación del alemán al español y viceversa tanto en el ámbito administrativo y diplomático en particular, como en el de las relaciones internacionales en general, de intercambio social, cultural, económico, político y científico. A partir del siglo XVIII la situación varia de forma drástica y el latín es la lengua empleada en la comunicación para resolver cualquier cuestión entre ambos territorios lingüísticos. Esto, lógicamente, se refleja en la producción lexicográfica posterior, de la que pasamos a dar cuenta a continuación.

\footnotetext{
${ }^{14}$ Sobre estas obras manejadas por Zumaran puede consultarse Corvo (2007: 31).
} 


\section{SIGLO XVIII: WÖRTERVERZEICHNISSE Y HANDWÖRTERBUCH ESPAÑOL- ALEMÁN}

Los primeros años del siglo XVIII no suponen evolución alguna de la producción lexicográfica español-alemana del periodo anterior. Y tampoco parece variar la situación del interés lingüístico del alemán por el español y del español por el alemán: este último continúa siendo prácticamente nulo, a diferencia del primero, que sigue mostrándose y materializándose en la publicación de nuevos manuales, en los que nuevamente debemos centrar nuestra atención, pues es en ellos donde se recogen los testimonios más destacables de la primera mitad de este siglo para la lexicografía bilingüe en alemán y español.

Entre los que hemos podido identificar en el tiempo de preparación de este trabajo, en primer lugar por orden temporal de aparición se encuentra: "El parte secondo. ò Nomenclator / Die Andere Abtheilung. Oder Einfache Wörter", incluido en el TeutschSpanischer Richtiger Und Regulmäßiger Sprach-Zeiger de 1712 y de cuyo autor se conocen tan sólo las iniciales con las que firma este trabajo: A. F. K.

Esta nomenclatura es un registro de palabras español-alemán ordenadas nach Sachgruppen o temáticamente que se extiende de la página 48 a la 125 de este manual de lenguas, el cual incluye además una breve introducción a la pronunciación de la lengua española, una panorámica gramatical y una colección de trece diálogos ${ }^{15}$.

El segundo testimonio lo constituye el "Wörterverzeichnis, z.T. nach Wortarten, z.T. nach Sachgruppen geordnet" (Wippich-Roháčková 2000: 101) que Antonio Moratori incluyó en las páginas 256-424 de su Instrucción fundamental de 1723, una obra que contiene otras partes junto a este vocabulario ordenado en parte por tipos de palabras o Wortarten y en parte por temas o nach Sachgruppen. Estas otras partes son: una colección de veintidós diálogos, refranes, sentencias morales, cuestiones varias sobre el aprendizaje de la lengua española, su pronunciación, tipos de palabras -como el artículo, el nombre, etc.- y la composición de cartas en español y alemán.

En la segunda mitad del siglo XVIII una serie de factores y nuevas circunstancias facilitan y estimulan la elaboración de nuevas obras lexicográficas en alemán y español; entre otras cosas, podemos recordar el hecho de que en el año 1782 comenzaron las relaciones diplomáticas entre Prusia y España y que dos años antes había visto la luz la primera edición abreviada del diccionario de la Real Academia Española ${ }^{16}$, que vino a allanar mucho el terreno de los lexicógrafos europeos a partir de entonces.

No obstante, y a diferencia de lo sucedido en la lexicografía bilingüe del español con las lenguas francesa e italiana, también esta segunda mitad de siglo resulta muy pobre y ninguna obra nueva aparecería hasta la última década del siglo, momento en el que localizamos los testimonios siguientes.

\footnotetext{
${ }^{15}$ Más en detalle puede consultarse en Wippich-Roháčková (2000: 100).

${ }^{16}$ Apareció en Madrid con el título de Diccionario de la lengua castellana. Reducido a un tomo para su más fácil uso (Niederehe 2005: 222).
} 
El primero nos llega de la mano de Johann Daniel Wagener, profesor de español, además de portugués y de italiano. Su labor como maestro de español, antes de llevarle a escribir una gramática española en 1795 -su Spanische Sprachlehre, nebst Übungen zur Anwendung der Grundsätze, der Wortfügung und der Schreibart der spanischen sprache, mit einer Einleitung in die Grundsätze der spanischen Sprache- le llevó en 1793 a publicar su libro de lectura Spanisches Lesebuch für Anfänger, en el que encontramos el primer testimonio lexicográfico de finales de siglo del que queremos dar cuenta: un registro de las palabras o diccionario, como aparece reseñado en junio de 1797: "Spanisches Lesebuch für Anfänger. Nebst einem Wörterbuch über die hierin erhaltenen Aufsätze"17.

El segundo es un registro de palabras o "índice de vocablos español y alemán” incluido en la traducción que Luis Henrique Teucher llevó a cabo en Leipzig en 1794 de la obra latina de Juan Amos Comenio La excelente puerta de las lenguas, o introducción al estudio de ellas por muchísimas descripciones de cosas corporales y morales ${ }^{18}$.

El tercer testimonio es un Handwörterbuch o diccionario manual que vio la luz también en Leipzig un año después. Se trata del primer tomo del Diccionario Español y Aleman oder Handwörterbuch der spanischen Sprache für die Deutschen de Ernst August Schmid, incluyendo la parte español-alemán con una extensión de 1902 columnas en 951 páginas (Fuentes 2000: 382). Schmid se basó para su elaboración en el Diccionario de la Real Academia, en el Nouveau dictionnaire espagnol français latin de Séjournant, en el Nouveau dictionnaire espagnol, françois et latin, et françois, espagnol et latin de Sobrino y en el diccionario español-inglés de Stevens ${ }^{19}$.

Este diccionario está prologado por Friedrich Justin Bertuch, intelectual del círculo de Weimar conocido, entre otras cosas, por ser un gran hispanista y traductor literario y quien lo presenta como el primer diccionario español-alemán publicado hasta el momento; el prólogo de Bertuch está fechado el 6 de abril de 1795 y textualmente dice: "Es erscheint also hier das erste spanisch-deutsche Wörterbuch für Deutsche. Die erste Bahn zu brechen, ist in jeder Sache schwer, und das Publikum wird daher billige Nachsicht mit diesem ersten Versuch haben" ${ }^{20}$.

Resulta interesante conocer los siguientes hechos en torno a la aparición de este diccionario: Bertuch, quien también es autor y editor del Manual de la lengua española. Oder Handbuch der Spanischen Sprache, für Anfänger, welche dieselbe erlernen wollen de 1790, había planeado un "kleines spanisch-deutsches Handlexicon" (Hausmann 1991: 2987), un diccionario manual español-alemán a continuación de su gramática, pero su editor, Engelhard Benjamin Schwickert, le encargó la elaboración de un diccionario

\footnotetext{
${ }^{17}$ En http://zs.thulb.uni-jena.de/receive/jportal_jparticle_00014680.

${ }^{18}$ Citamos a través de Niederehe (2005: 287).

${ }^{19}$ Schlipf (1956-1957: 190) y Marín (1992: 176-177) también mencionan la influencia del diccionario españolholandés de Horkens; sobre esto, contrástese con Hausmann (1991: 2987) y Fuentes (2000: 382). Las diferentes ediciones de los diccionarios mencionados en el cuerpo del texto pueden consultarse en Niederehe (2005: 346 [Real Academia], 470 [Séjournant], 470-471 [Sobrino] y 471 [Stevens]).

${ }^{20}$ Citamos a través de Schlipf (1956-1957: 191).
} 
completo. Sin embargo, Bertuch finalmente no llevó a cabo este encargo y sería el bibliotecario de Weimar, Ernst August Schmid, el responsable de hacerlo. Años después también se encargaría de su segunda parte, la de alemán-español, aparecida después del diccionario de Wagener ya en el siglo XIX.

Las relaciones entre España y Alemania llegando al final de siglo se hallan muy reforzadas y prueba del intercambio más fluido en el terreno comercial entre españoles y alemanes es la siguiente obra de Friedrich Benjamin Bucher, aparecida en Leipzig en 1797, que queremos mencionar como último testimonio de este siglo.

La obra lleva por título Manual para los Negociadores Españoles y Alemanes, oder Spanischer Lesebuch für den Kaufmann y entre otro vocabulario, por ejemplo, recoge un "Verzeichnis aller Arten von Geweben, und der dazu erforderlichen Werkzeuge", es decir, un registro con todo tipo de tejidos y las herramientas que éstos requieren.

A través de la reseña que de esta obra se hizo en septiembre de 1801, sabemos que fue presentada como manual para los comerciantes alemanes interesados en aprender el español en una época caracterizada por el crecimiento constante de las actividades comerciales alemanas con España, tal como recogen las siguientes palabras:

[...] so muss doch der Kaufmann jetzt das Bedürfnis lebhaft fühlen, sich mit der Sprache dieser Nation bekannt zu machen, da unser Handel mit Spanien jedes Jahr bedeutender und ausgebreiteter wird. Deshalb bearbeitete Hr. B. dieses Lesebuch, damit der deutsche Kaufmann durch diese Lectüre, mit Hülfe eines Wörterbuchs (etwa von Gattel $^{21}$ ) und einer brauchbaren Sprachlehre (wie die von Wagener) in den Stand gesetzt werde, die Sprache, in so weit er sie zu seinem Handelsberufe nöthig hat, wenigstens bis zum Briefschreiben, in seine Gewalt zu bekommen ${ }^{22}$.

\section{Siglo XIX: Del Handwörterbuch al GrosswörterbuCh y al TASCHENWÖRTERBUCH}

A partir del año 1800 comienza una nueva etapa en la historia de la lexicografía bilingüe española y alemana, que arranca con la publicación del Neues und vollständiges Spanisch-Deutsch und Deutsch-Spanisches Wörterbuch del teólogo, notario, traductor y lexicógrafo Johann Daniel Wagener y que es el primer gran diccionario bilingüe conocido conteniendo este par de lenguas.

En su conjunto, esta obra consta de cuatro tomos. Los dos primeros configuran el diccionario español-alemán y fueron publicados en primer lugar, en 1800; la portada del tomo primero, que recoge las letras A-F, es como sigue:

Nuevo diccionario español-aleman y aleman-español por Juan Daniel Wagener. Tomo primero que contiene el Diccionario Español-Aleman aumentado con muchísimas

\footnotetext{
${ }^{21}$ Se refiere al Nouveau dictionnaire espagnol et françois, françois et espagnol. Avec l'interprétation latine chaque mot de Claude Marie Gattel, publicado en Lyon poco antes, en 1790.

${ }^{22}$ En http://zs.thulb.uni-jena.de/receive/jportal_jparticle_00019762.
} 
voces importantísimas, que no se encuentran en los otros diccionarios hasta ahora publicados. Hamburgo y Altona MDCCC. Y se hallará en casa de Gottfriedo Vollmer ${ }^{23}$.

Los tomos tercero y cuarto, conteniendo el diccionario alemán-español, aparecieron un año después, en 1801, y aunque ocupan la mitad de la extensión de los tomos anteriores, este diccionario alemán-español supone un hito en la historia de la lexicografía bilingüe española y alemana por ser el primer diccionario concebido a partir de la lengua alemana con el que cuenta esta disciplina.

En 1805, como ya advertíamos anteriormente, ve la luz la segunda parte del diccionario de Schmid, la de alemán-español, para cuya elaboración su autor contó con la colaboración de L. H. Teucher.

La producción de estos diccionarios en estos primeros años del siglo XIX refleja el nuevo camino que a partir de entonces inicia la actividad lexicográfica bilingüe en español y alemán con la intención de dar respuesta a una demanda cada vez mayor de diccionarios de fácil manejo de español. De acuerdo con Hausmann 1991: 2988, principalmente en las ciudades portuarias de Hamburgo y de Bremen comienza a ser muy solicitado el formato de bolsillo y esto justifica la aparición de los siguientes diccionarios: el Kurzgefaßtes spanisch-deutsches und deutsch-spanisches Taschenwörterbuch de Daniel Braubach de 1807, los dos tomos del Kurzgefaßtes spanisch-deutsches und deutsch-spanisches Taschenwörterbuch o Diccionario de faltriquera, o sea portátil [...] de Johann Daniel Wagener de 1808 y 1809, respectivamente, el Spanisch-deutsches [...] Taschenwörterbuch für Kaufleute, Correspondenten und Sachführer de P. Deranco de 1829 y el SpanischDeutsches Wörterbuch zu dem Spanischen Lesebuch de Victor Aimé Huber de 1832.

Junto al constante aumento de las relaciones comerciales entre España y Alemania a lo largo de este siglo, otras razones que nos ayudan a entender la proliferación experimentada por la realización en Alemania de diccionarios con el español son las siguientes: el renovado interés de los hispanistas alemanes por la literatura española, como prueba el especial interés despertado por la obra cervantina, que ya había traducido Bertuch en 1775 y que cuenta ahora en este siglo con su traducción integra de la mano de Ludwig Tieck, publicada entre los años 1799 y 1801 en la ola del atractivo por España y por lo español de la corriente romántica alemana ${ }^{24}$; la gran simpatía que en el pueblo alemán despertó la victoria de los patriotas españoles en la Guerra de la Independencia contra Napoleón y la perspectiva de nuevas relaciones comerciales con Hispanoamérica.

Así, como resultado de la acogida de la obra cervantina en Alemania, ya en la primera década del siglo apareció el diccionario español-alemán de Benecke para acompañar la edición de 1798 de Don Quijote de la Mancha. Este Spanisch-deutsches Wörterbuch zum Don Quijote de Johann Basilius Wilhelm Benecke, que sigue resultando de utilidad incluso

\footnotetext{
${ }^{23}$ Citamos a través de Niederehe (2005: 317).

${ }^{24}$ La traducción de Bertuch, titulada Leben und Taten des weisen Junkers Don Quixote von Mancha, fue reimpresa hasta cinco veces en el último cuarto del siglo XVIII; la última reimpresión es de 1798. Sobre las diferentes ediciones de la traducción de Tieck puede consultarse Barsanti (2004).
} 
en la actualidad, fue editado en diferentes ocasiones ${ }^{25} \mathrm{y}$, como decimos, testimonia el grado de popularidad alcanzado en Alemania por la novela de Cervantes en este siglo.

Y la última de las razones aludidas es la que explica la publicación del Diccionario de las lenguas española y alemana de Theresius von Seckendorff, dedicado a Ludwig Karl August von Bayern -Luis I a partir del año 1825-, amigo de la lengua y literatura españolas, y destinado principalmente a los comerciantes e interesados en emigrar a Sudamérica $^{26}$.

Es un diccionario concebido en tres tomos: los dos primeros, aparecidos uno en 1823 y otro en 1824, contienen respectivamente las partes relativas a las letras A-E y F-Z de la combinación de lenguas español-alemán; y el tercero es el diccionario alemán-español, terminado por Christian Martin Winterling en 1828 y que fue publicado a un mismo tiempo en dos ciudades, de mano de Perthes y Besser en Hamburgo y de Riegel y Wießner en Núremberg.

Con la siguiente advertencia del editor: "Por lo demás, este diccionario es el primer diccionario español-alemán, que ha admitido la nueva ortografía" ${ }^{\text {,27 }}$, se publica en Leipzig en 1829 la parte español-alemán del Neues Spanisch-Deutsches und Deutsch-Spanisches Wörterbuch de Franceson ${ }^{28}$; el segundo tomo de este diccionario, que contiene la combinación de lenguas inversa, apareció en 1933, un año después de que viera la luz en Bremen un nuevo diccionario de bolsillo, el Spanisch-Deutsches Wörterbuch zu dem Spanischen Lesebuch de Victor Aimé Huber con 118 páginas.

Finalizando la primera mitad de siglo, el mayor acercamiento entre España y Alemania comienza a tener sus frutos también en el panorama editorial español, lo que evidencia por primera vez el interés por la lengua alemana de los españoles, atraídos por su cultura primero y por la destacada posición en Europa de la ciencia y de la tecnología alemanas después. Y junto a otros manuales publicados en Alemania, también comienzan a aparecer otras gramáticas alemanas salidas tanto de imprentas españolas, como de otros países,

\footnotetext{
${ }^{25}$ Los datos encontrados sobre este diccionario no resultan claros. En Niederehe (2005: 312) se recoge fechado en el año 1800 y del siguiente modo: "Spanisch-deutsches Wörterbuch zum Don Quijote. Als 8. Bd. zu der Ausgabe des Don Quijote. Leipzig: J. Sommer”. En el Pierer's Universal-Lexicon se cita la edición de Madrid de la obra cervantina "mit Diccionario español-alemán v. Benecke, Lpz. 1800-7, 6 Bde." (en http://www.zeno.org/Pierer1857/A/Cervantes-Saav\%C4\%93dra). Y Kraus et al. (1984: 92) mencionan la edición de Berlín de 1842 de este diccionario y también otras anteriores aparecidas en Leipzig en 1808 y 1821 como Erklärung aller im Don Quixote vorkommenden und diesem Werke vorzüglich eigenen schweren Wörter und Redensarten.

${ }^{26}$ Cf. Schlipf (1956-1957: 199) y Hausmann (1991: 2988). Seckendoff elaboró su diccionario a partir de un trabajo manuscrito anterior que en cinco tomos recogía un diccionario bilingüe en español y francés concluido en 1723 por Leiss, un maestro de lenguas de la entonces Universidad de Altdorf y posterior Universidad de Erlangen. Cf. Schlipf (1956-1957: 198) y Fuentes (2000: 384)

${ }^{27}$ Pues presenta la nueva ortografía del castellano, a diferencia del de Seckendorff; citamos a través de Schlipf (1956-1957: 203)

${ }^{28}$ Franceson también fue maestro de francés en Berlín, donde publicó su Neue französische Sprachlehre für Deutsche en 1809. Su Grammatik der Spanischen Sprache fue mucho posterior, pues apareció en Leipzig en 1843.
} 
redactadas en castellano para satisfacer la creciente demanda para aprender la lengua alemana de cara a futuros negocios hispano-alemanes en España y en Hispanoamérica ${ }^{29}$.

Las circunstancias propias de la época favorecieron esta actividad: por un lado, en Europa el ferrocarril acortaba las distancias, facilitando la comunicación por tierra y, por otro lado, también América Central y América del Sur resultaban objetivos de mercado más fáciles por mar desde que la Hamburg-Amerikanische Paketfahrt-Aktiengesellschaft -o Hapag- dispusiera en 1856 de una línea regular en barco desde Hamburgo.

Respondiendo a esta nueva situación de mediados de siglo, en 1858 se publicó en Leipzig el siguiente diccionario manual de este siglo: el Nuevo Diccionario de la Lenguas Castellana y Alemana, el más completo que se ha publicado hasta el día. Neuestes und vollständigstes Spanisch-Deutsches und Deutsch-Spanisches Handwörterbuch del director de la Escuela de Comercio de Lepzig Friedrich Booch-Árkossy, intelectual políglota y coautor de otros diccionarios de alemán con las lenguas polaca y rusa, así como autor de manuales, gramáticas y libros de diálogos de estas y otras lenguas. Con sus dos tomos, conteniendo la parte español-alemán el primero en un total de 1132 páginas y la parte alemán-español el segundo a lo largo de sus 704 páginas, conoció su séptima edición en 1887, lo que nos habla de la gran acogida que experimentó este diccionario en su época.

En torno a su publicación se conocen los siguientes hechos: en un principio, la editorial B. G. Teubner le había encargado la elaboración de este diccionario al director de la Escuela de Comercio de Gotta F. E. Feller, autor de otros diccionarios publicados por esta misma editorial, pero éste, ante la imposibilidad de atender este encargo en el tiempo requerido, se lo ofreció a Booch-Árkossy, poniéndose a su disposición para que contara con su ayuda. Finalmente, además, Árkossy también contó con la ayuda del comerciante O. Rieger, quien colaboró en la inclusión de gran parte de vocabulario técnico y comercial (Schlipf 1956-1957: 211-213, Fuentes 2000: 386). El peso de este tipo de vocabulario específico es grande en este diccionario y este hecho queda reflejado en la portada del mismo del siguiente modo:

Nuevo diccionario [...] Mit Benutzung der Wörterbücher von Salvá, Blanc, Rosa, Seckendorff, Domínguez und einer grossen Anzahl Spezialschriften aller Art nach dem jetzigen Stande der Literatur und mit besonderer Rücksicht auf Wissenschaften, Künste, Industrie und Handel bearbeitet ${ }^{30}$.

El éxito de este diccionario fue tan rápido que, tras la tercera edición en 1862, la editorial decidió sacarlo al mercado también en versión reducida, para lo que encargó a Friedrich Booch-Árkossy que lo redujera al formato de un diccionario de bolsillo. Y así, en 1863 vio la luz en Leipzig el Neuestes und vollständigstes Taschenwörterbuch der

\footnotetext{
${ }^{29}$ Como las gramáticas de Kühn o Braun, aparecidas en Madrid en 1844 y 1864, respectivamente, la de Fernández de Castroverde, publicada en Barcelona en 1868, o la de Pablo Kohl de 1897, aparecida en Zúrich con la siguiente portada: Libro para la enseñanza de la lengua alemana. Gramática construida sobre la triple base de la enseñanza objetiva, de la Conversación i de la lectura. En conformidad con el plan de estudios $i$ el programa aprobados por el Consejo de Instrucción Pública de Chile [...]. Resulta muy ilustrativo al respecto el trabajo de Marizzi de 2001.

${ }^{30}$ Citamos a través de Schlipf (1956-1957: 212).
} 
spanischen und deutschen Sprache. Consta de dos tomos de 696 y 526 páginas, respectivamente y, como el primero, gozó igualmente de una buena acogida, llegando a conocer su séptima edición en 1893.

La intensificación del tráfico comercial en la segunda mitad de siglo llevó a la mayor demanda de auxilios lingüísticos y, al inicio del último cuarto de siglo, a los manuales específicos para comerciantes que se empezaron a publicar en estos años se unió la publicación en Bremen en 1875 del primer diccionario bilingüe comercial en alemán y español, el Deutsch-Spanisches und Spanisch-Deutsches Wörterbuch des kaufmännischen Verkehrs und der Handelskorrespondenz del hispanista H. W. A. Kotzenberg, quien en el prólogo lo presentó como un diccionario de bolsillo útil para los viajes (Schlipf 1956-1957: 223), de ahí su formato en un único tomo dividido en las dos partes mencionadas, la primera con un total de 268 páginas y la segunda con 218.

En esta misma línea de utilidad concibió Heinrich Ruppert su Spanischer Sprachführer. Konversations-Wörterbuch, publicado en Leipzig y en Viena en 1887. Este diccionario de bolsillo consta de tres partes: un diccionario de conversación alemán-español con un total de 454 páginas, un pequeño vocabulario español-alemán de poco más de cincuenta páginas pensado para la comprensión del vocabulario elemental que el viajero alemán se encontraba en los rótulos e indicaciones públicos, en las tiendas o en los menús de los restaurantes y un anexo gramatical con el que concluye la obra en la página 526.

Es interesante llamar la atención sobre el hecho de que se trata de la obra de un alemán asentado en España desde 1873, que conocía muy de cerca las necesidades del viajero alemán, lo que explica que en su mayor parte se trate de un repertorio alfabético de palabras y expresiones alemanas con sus correspondencias españolas. Para su elaboración Ruppert contó con la ayuda de sus colegas del Colegio de la Esperanza de Madrid José Aguilera y Manuel Rodríguez Navas (Schlipf 1956-1957: 224 y ss.).

Acercándonos a la última década, nos encontramos con otro gran diccionario del siglo XIX, el Nuevo Diccionario español-alemán y alemán-español del hispanista y en su día Cónsul General francés Louis Tolhausen; se publicó en Leipzig en dos tomos: el primero, con la parte español-alemán, es de 1888 y consta de 764 páginas y el segundo, con la parte alemán-español, es de 1889 y consta de 825 páginas. Y con ello estamos ante el primer gran diccionario con el que cuenta la historia de lexicografía bilingüe en alemán y español en el que la parte alemana presenta una dimensión similar a las partes español-alemán conocidas hasta ese momento.

A pesar de las críticas de la que fue objeto por los más entendidos ${ }^{31}$, gozó de un enorme éxito editorial y llegó a conocer hasta diez ediciones, siendo la última publicada en el año 1928.

Y ya de la última década del siglo XIX son los siguientes diccionarios: el Diccionario Español-Alemán y Alemán-Español de Arturo Enenkel, el Taschenwörterbuch der Spanischen und deutschen Sprache de Hans Ossig, el Taschenwörterbuch der spanischen

\footnotetext{
${ }^{31}$ Remitimos al trabajo de Schlipf (1956-1957: 228 y ss.).
} 
und deutschen Sprache de Moesch y Diercks y el Neues Spanisch-Deutsches und DeutschSpanisches Wörterbuch de Theodor Stromer.

El filólogo alemán Enenkel, autor también de otros diccionarios bilingües con el alemán -de italiano y de portugués-, publicó su diccionario en París en el año 1891 y lo presentó del siguiente modo:

Diccionario Español-Alemán y Alemán-Español, el más completo de los publicados hasta el día que abraza los términos literarios y los del lenguaje usual en su sentido propio y figurado, las voces usadas en las artes y oficios, los nombres propios de personas, de Geografía y Mitología, según los mejores diccionarios españoles y alemanes, aumentado con una tabla de los verbos irregulares ${ }^{32}$.

Este diccionario consta de un único volumen dividido en dos partes: la españolaalemana con un total de 590 páginas y la alemana-española con 500 páginas. De acuerdo con Hausmann (1991: 2988), es un producto de su editor, Garnier Frères, y el primero hecho a la medida del usuario español. El propio Enenkel así lo creyó también y dejó expresada esta idea en el prólogo del mismo a través de las siguientes palabras:

Sólo faltaba en España un Diccionario alemán compuesto según el uso moderno y las reglas recibidas y establecidas [...] se han ocupado exclusivamente de proporcionar a los alemanes la explicación de las palabras españolas [...] No es lo mismo de la parte alemana, que se puede decir nos era preciso crear, siendo que nuestros predecesores no han hecho más que lo que podía ser de utilidad a los alemanes, explicando el alemán por sí mismo, y de esta manera sus trabajos fueron inútiles para los españoles ${ }^{33}$.

En las páginas iniciales, Garnier Frères lo presenta como "un manual asaz completo para no ser consultado inútilmente tanto en los estudios complicados como en los viajes"34 $\mathrm{y}$, aunque con carencias, lo cierto es que su configuración práctica sirvió de modelo para otros diccionarios posteriores, como el de Moesch y Diercks.

La aparición de éste último, como la del de Ossig, nos permiten comprender que a estas alturas del siglo se han intensificado las relaciones hispano-alemanas y el formato del diccionario de bolsillo resulta muy práctico como herramienta lingüística en los desplazamientos tanto a España como a América. Ambos diccionarios coinciden en que fueron publicados en la ciudad de Leipzig y en que presentan las dos partes en un único volumen.

En el de Ossig la parte española-alemana es la primera y consta de 256 páginas; la segunda, la alemana-española, contiene 257 páginas. F. Moesch, coautor junto a G. Diercks del diccionario, es el responsable de la primera parte, que en este caso está dedicada a la combinación de lenguas alemán-español y consta de un total de 450 páginas; la segunda, la

\footnotetext{
${ }^{32}$ Citamos a través de (Schlipf 1958: 303).

${ }^{33}$ Citamos a través de Schlipf (1958: 304-305); entre otras ventajas en cuanto al fin práctico de este diccionario, Schlipf menciona la siguiente: "Bisher war H. Ruppert der einzige Lexikograph, der seinem Wörterbuch durch angefügte Konjugationsübersichten eine erhöhte Brauchbarkeit gegeben hatte. Enenkel ging noch einen Schritt weiter, indem er eine schärfere logische Ordnung in das System der Tabellen und Formen brachte” (p. 307).

${ }^{34}$ Citamos a través de Schlipf (1958: 310).
} 
española-alemana, es obra de Diercks y es un poco más extensa que la anterior, pues cuenta con 490 páginas. De acuerdo con Hausmann (1991: 2988), la obra de Moesch-Diercks "enthält die beste Glossierung und Phraseologie" y está en la frontera del Handwörterbuch.

El de Stromer, editado en Berlín por F. A. Herbig, es el último diccionario bilingüe en español y alemán publicado antes del siglo XX. Se trata de un Handwörterbuch dividido en dos tomos: el primero, con la combinación español-alemán a lo largo de 828 páginas, salió publicado en 1897 y el segundo, con la combinación de lenguas inversa y con 812 páginas, tres años después. Y como los anteriores de esta última década de siglo, fue concebido con un fin práctico, para que resultara de utilidad tanto a los hablantes de español como de alemán y tanto al sector comercial como al industrial.

\section{Comentarios Finales}

En el siglo XVI el español, como una de las principales y grandes lenguas internacionales de Europa de la época junto con el francés, ya contaba con aportaciones bilingües muy tempranas tanto en combinación con el latín, como con otras lenguas modernas ${ }^{35}$; a principios del siglo siguiente, además, ya conoció sus primeros diccionarios monolingües ${ }^{36}$.

Estos hechos que convierten a España en pionera en el campo de las lexicografías monolingüe y bilingüe no impiden, sin embargo, que siempre haya ido por detrás de las principales lenguas europeas en lo que a la lexicografía bilingüe con la lengua alemana se refiere, ya que, como sabemos, hubo que esperar hasta el siglo XVII para que comenzara su andadura con la nomenclatura bilingüe de Juan Ángel de Zumaran y con el diccionario español-alemán de Mez de Braidenbach.

En estos siglos la lengua alemana ocupaba una posición más débil en el panorama lingüístico europeo y esto explica que, salvo gloriosas excepciones, como lo fueron los diccionarios de Levinus Hulsius, en los diccionarios bilingües el alemán no fuera tratado como lengua de partida hasta el siglo XVIII, momento en el que se elaboraron, por ejemplo, los primeros diccionarios de alemán-francés, alemán-inglés y otros ${ }^{37}$.

\footnotetext{
${ }^{35}$ De hecho, uno de los más importantes diccionarios del español es el Diccionario español-latino de Nebrija de 1495; sobre las diferentes ediciones con el español puede consultarse el trabajo de Niederehe de 1994

${ }^{36}$ Francisco del Rosal terminó en 1601 su Origen y etimología de todos los vocablos originales de la lengua castellana, el primer diccionario monolingüe de una lengua europea, aunque no lo publicó; el primero en salir publicado fue el Tesoro de la lengua castellana o española de Covarrubias, que apareció en Madrid en 1611 -es decir, un año antes de Il memoriale de la lengua, más conocido como el Pergamino- y que es uno de los más importantes diccionarios del español junto al Diccionario de autoridades (1726-1739), ya en el siglo XVIII, y a los no académicos del siglo XIX

${ }^{37}$ En 1716 Thomas Fritsch editó en Leipzig el Teutsch-Englisches Lexikon, atribuido a Ludwig Christian, maestro de inglés en esta ciudad (Hausmman / Cop 1985: 187); con anterioridad, entre los años 1700 y 1702, había aparecido en Núremberg Das herrlich Große Teutsch-Italiänische Dictionarium de Matthias Kramer, autor también del primer diccionario holandés-alemán y alemán-holandés de 1719.
} 
No obstante, en lo que a la combinación con la lengua española se refiere, hay que esperar hasta la aparición del diccionario de Tolhausen en el siglo XIX para poder encontrar por primera vez en la historia de la lexicografía bilingüe de estas lenguas una parte alemana-española con una entidad comparable a la de español-alemán. Posiblemente esto puede explicarse aludiendo a diferentes motivos que hemos tenido ocasión de conocer en este trabajo: porque casi todos los diccionarios bilingües en alemán y español publicados hasta entonces habían ido dirigidos principalmente al usuario de habla alemana, porque sus autores casi siempre fueron hablantes alemanes y porque siempre y hasta el siglo $\mathrm{XX}$ fueron publicados fuera de España.

Vistos en su conjunto, los diccionarios que siguieron al de Mez, hasta el de Tolhausen, responden a los dos tipos siguientes según el receptor: en su mayoría son Herübersetzungswörterbücher, ya que en ellos el usuario encuentra la lengua extranjera como lengua de partida y la materna como lengua de llegada, y sólo a partir del siglo XIX aparecieron también los Hinübersetzungswörterbücher, en los que el usuario tiene la lengua materna como lengua de partida y la extranjera como lengua de llegada.

$\mathrm{Y}$, de acuerdo con las características que les son propias en su concepción, en cuanto a formato y dimensión, responden a la siguiente caracterización ${ }^{38}$ :

$\begin{array}{lll}\text { (Gran diccionario) } & \text { (Diccionario manual) } & \text { (Diccionario de bolsillo) } \\ \text { Wagener 1800-1801 } & \text { Wagener 1795 } & \text { Braubach 1807 } \\ \text { Seckendorff 1823-1824 } & \text { Schmid 1805 } & \text { Wagener 1808-1809 } \\ \text { Tolhausen 1888-1889 } & \text { Francescon 1829-1833 } & \text { Deranco 1829 } \\ & \text { Booch-Árkossy 1858 } & \text { Huber 1832 } \\ & \text { Enenkel 1891 } & \text { Booch-Árkossy 1863 } \\ & & \text { Kotzenberg 1875 } \\ & & \text { Ruppert 1887 } \\ & \text { Ossig 1894 } \\ & \text { Moesch-Diercks 1895-1896 } \\ & \text { Stromer 1897-1900 }\end{array}$

Junto a los diccionarios, que son semasiológicos y tienen una ordenación alfabética, en este estudio también nos hemos ocupado de otro tipo de repertorios lexicográficos, como las nomenclaturas, que son onomasiológicos y responden a una ordenación temática del contenido que generalmente no sigue un orden alfabético. Básicamente, además, tienen un carácter descriptivo, ya que son obras didácticas que intentan compilar una selección del vocabulario básico, útil y necesario de forma ordenada y sin criterios puristas.

\footnotetext{
${ }^{38}$ Nos hemos guiado básicamente por Hausmann (1991: 2988).
} 
Si bien nuestro objetivo en estas páginas ha sido presentar un inventario de repertorios bilingües, al inicio de nuestro recorrido histórico también nos hemos referido a otros compendios multilingües con la intención de aclarar que la primera coincidencia del par de lenguas español y alemán se registra dentro de los vocabularios multilingües. Por ello, dentro de este conjunto, hemos tratado de mencionar fundamentalmente aquellas ediciones en las que por primera vez en la Historia aparecían juntas las lenguas española y alemana, aunque también hemos recordado algún caso curioso, como el vocabulario trilingüe en francés, alemán y español incluido en la edición de Amberes de 1552 de la obra de Vives.

Las recopilaciones bilingües, esporádicas y menos frecuentes en aquellos años, fueron concebidas como auxilios lingüísticos muy prácticos y, como las multilingües, consistían en listas sencillas de artículos de mercancías con un único equivalente para cada palabra la mayoría de las veces, ya que sus destinatarios eran principalmente los viajeros y comerciantes extranjeros interesados en aprender una de las lenguas recogidas en ellos ${ }^{39}$.

Con idéntica intención práctica concibió Juan Ángel de Zumaran sus nomenclaturas. Y también la última, la bilingüe español-alemana incluida en su último libro de lenguas de 1634 , con la que hemos arrancado el camino trazado por aquellas obras y autores que a lo largo de los siglos XVII, XVIII y XIX han protagonizado la historia de la lexicografía bilingüe española y alemana anterior al siglo XX.

Esta nomenclatura aparece en estas páginas por primera vez como el primero de los hitos tratados en un estudio de esta naturaleza y constituye la principal aportación de este trabajo, concebido, como advertíamos inicialmente, para completar otros anteriores y poder así comprender de mejor manera el desarrollo histórico de la lexicografía bilingüe española y alemana hasta el siglo XIX, en el que también han participado este otro tipo de repertorios léxicos menores, como hemos intentado plasmar brevemente en estas páginas, y que en orden cronológico de aparición comprende, al menos, las obras incluidas en la tabla del apartado siguiente.

\section{TABLA DE OBRAS}

A continuación recogemos los vocabularios y diccionarios mencionados a lo largo de este trabajo en estricto orden cronológico. Tras el año de aparición, el nombre del autor y el título, aparece el nombre del lugar de publicación en su versión original y el del impresor y/o editor en caso de que nos sea conocido:

1634. J. Á. de Zumaran. Nomenclatura muy cumplida de todos los vocablos mas necessarios, que ocurren y son menester para la comunicación cotidiana [...] Ein volkomenliche Nomenclatur aller notwendigisten Wórtern die zu der táglichen Communication von nóthen seynd. (Parte tercera de la Grammatica y Pronunciación

\footnotetext{
${ }^{39}$ La elaboración de los compendios de vocabulario bilingüe es una práctica muy antigua en Europa. La lengua alemana, por ejemplo, se recoge ya a partir del siglo VII junto al latín en forma de glosas insertadas al margen, entre líneas o al final del texto. El glosario bilingüe alfabético más antiguo conocido es el Abrogans del siglo VIII y el Vocabulario de Sankt Gallen, también del siglo VIII, es un ejemplo de un compendio ordenado por materias.
} 
alemana y española. Española y Alemana. Compuesta en beneficio de estas dos Naciones, que quieren aprender una destas lenguas [...] Teutsche und Spannische/ Spannische und Teutsche Grammatica und außsprach [...], Viena, M. Riccio).

1666. N. Mez de Braidenbach. Nomenclatur, für diejenigen so eine dieser Sprachen verlangen zu lernen zusammen getragen (En su Gramatica o Instrucción Española y Alemana, compuesta con un metodo nuevo, y muy facil; con algunas Sentencias Refranes, Versos, y exemplos para escribir Cartas [...], Viena, S. Rickesin).

1670. N. Mez de Braidenbach. Diccionario muy Copioso de la lengua Española y Alemana, hasta agora nunca visto, Sacado De diferentes Autores con mucho trabajo y diligencia por Nicolás Metz de Braidenbach, Maestro en Artes, y notario Ces P. Con Licencia y Privilegio Sac. Caes. M.S., Viena, J. J. Kürner.

1712. A. F. K. Nomenclator. Oder Einfache Wörter incluido el Teutsch-Spanischer Richtiger Und Regulmäßiger Sprach-Zeiger (Segunda parte de Teutsch-Spanischer Richtiger Und Regulmäßiger Sprach-Zeiger [...], Núremberg, J. L. Buggel).

1723. A. Moratori. Un Lexicon Español, y Tudesco. Un vocabulario Alemán, y español (Partes cuarta y quinta de la Instrucción fundamental Para Aprendèr el idioma español [...], Núremberg, K. Monath).

1793. J. D. Wagener. Spanisches Lesebuch für Anfänger. Nebst einem Wörterbuch ubre die hierin erhaltene Aufsätze, Hamburgo, Hoffmann.

1794. J. A. Comenius, ed. por L. H. Teucher. La excelente puerta de las lenguas, o introducción al estudio de ellas por muchísimas descripciones de cosas corporales y morales. Obra traducida del latín de Juan Amos Comenio por Luis Enrique Teucher, y por el mismo aumentada de un indice de vocablos español y alemán, Leipzig, Schwickert.

1795. E. A. Schmid. Diccionario español y alemán oder Handwörterbuch der Spanischen Sprache für die Deutsche. Mit einer Vorrede des Legationsrats Bertuch (t. I: españolalemán), Lepizig, Schwickert.

1797. F. B. Bucher. Manual para los Negociadores Españoles y Alemanes, oder Spanischer Lesebuch für den Kaufmann, enthaltend eine Reihe zweckmässiger merkantilischer Aufsätze, Sacherklärungen und Briefmuster, Leipzig, Göthe.

1800. J. D. Wagener. Neues und vollständiges Spanisch-Deutsches und Deutsch-Spanisches Wörterbuch [...] Diccionario Español-Alemán, Hamburgo / Altona, G. Vollmer.

180_? J. B. W. Benecke. Spanisch-deutsches Wörterbuch zum Don Quijote, Leipzig, J. Sommer?

1801. J. D. Wagener. Neues und vollständiges Spanisch-Deutsches und Deutsch-Spanisches Wörterbuch [...] Dritter und vierter Band, welche das Deutsch-Spanische Wörterbuch enthalten, Hamburgo / Altona, G. Vollmer.

1805. E. A. Schmid, con la colaboración de L. H. Teucher. Diccionario Alemán y Español. Segundo tomo: alemán-español, Leipzig, Schwickert. 
1807. D. Braubach. Kurzgefaßtes spanisch-deutsches und deutsch-spanisches Taschenwörterbuch, Bremen.

1808. J. D. Wagener. Diccionario de faltriquera, o sea portátil [...] Kurzgefaßtes spanischdeutsches und deutsch-spanisches Taschenwörterbuch (t. I: español-alemán), Berlín.

1809. J. D. Wagener. Diccionario de faltriquera, o sea portátil [...] Kurzgefaßtes spanischdeutsches und deutsch-spanisches Taschenwörterbuch (t. II: alemán-español), Berlín.

1823. Th. Freiherr von Seckendorff. Diccionario de las lenguas española y alemana (t. I: A-E), Hamburgo, Perthes \& Besser; Núremberg, Riegel \& Wiessner (imprenta de F. Hofmann).

1824. Th. Freiherr von Seckendorff. Diccionario de las lenguas española y alemana (t. II: F-Z), Hamburgo, Perthes \& Besser; Núremberg, Riegel \& Wiessner (imprenta de F. Hofmann).

1828. Th. Freiherr von Seckendorff. Diccionario de las lenguas española y alemana (t. III: alemán-español, terminado por Christian Martin Winterling), Hamburgo, Perthes \& Besser; Núremberg, Riegel \& Wiessner (imprenta de F. Hofmann).

1829. P. Deranco. Spanisch-deutsches, portugiesisch-deutsches und deutsch-spanisches Taschenwörterbuch für Kaufleute, Correspondenten und Sachführer, Hamburgo.

1829. C. F. Franceson. Neues Spanisch-Deutsches und Deutsch-Spanisches Wörterbuch. Nach der neuesten, seit 1815 von der Spanischen Akademie sanktionierte Orthographie (t. I: español-alemán), Leipzig, F. Fleischer.

1832. V. A. Huber. Spanisch-Deutsches Wörterbuch zu dem Spanischen Lesebuch, Bremen, J. G. Heyse.

1833. C. F. Franceson. Neues Spanisch-Deutsches und Deutsch-Spanisches Wörterbuch. Nach der neuesten, seit 1815 von der Spanischen Akademie sanktionierte Orthographie (t. II: alemán-español), Leipzig, F. Fleischer.

1858. F. Booch-Árkossy. Nuevo Diccionario de las Lenguas Castellana y Alemana, el más completo que se ha publicado hasta el día [...], Leipzig, B. G. Teubner.

1863. F. Booch-Árkossy. Neuestes und vollständigstes Taschenwörterbuch der spanischen und deutschen Sprache, Leipzig, B. G. Teubner.

1875. H. W. A. Kotzenberg. Deutsch-Spanisches und Spanisch-Deutsches Wörterbuch des Kaufmännischen Verkehrs und der Handelskorrespondenz, Bremen, I. G. Heyse.

1887. H. Ruppert. Spanischer Sprachführer. Konversations-Wörterbuch. Leipzig / Viena, Verl. des Bibliographischen Instituts.

1888. L. Tolhausen. Nuevo Diccionario español-alemán y alemán-español. Neues spanisch-deutsches und deutsch-spanisches Wörterbuch (t. I: español-alemán), Leipzig, B. Tauschnitz. 
1889. L. Tolhausen. Nuevo Diccionario español-alemán y alemán-español. Neues spanisch-deutsches und deutsch-spanisches Wörterbuch (t. II: alemán-español), Leipzig, B. Tauschnitz.

1891. A. Enenkel. Diccionario Español-Alemán y Alemán-Español [...], París, Garnier Frères.

1894. H. Ossig. Taschenwörterbuch der Spanischen und deutschen Sprache, Leipzig, Ph. Reclam jun.

1896. F. Moesch, G. Diercks. Taschenwörterbuch der spanischen und deutschen Sprache, Leipzig, O. Holtzes Nachfolger.

1897. Th. Stromer. Neues Spanisch-Deutsches und Deutsch-Spanisches Wörterbuch (t. I: español-alemán), Berlin, F. A. Herbig.

1890. Th. Stromer. Neues Spanisch-Deutsches und Deutsch-Spanisches Wörterbuch (t. II: alemán-español), Berlín, F. A. Herbig.

\section{REFERENCIAS BIBLIOGRÁFICAS}

Ahumada, I. (ed.) (2000). Cinco siglos de lexicografía del español. IV Seminario de Lexicografía Hispánica. Jaén, 17 al 19 de noviembre de 1999, Jaén, Universidad de Jaén.

Alvar EzQuerra, M. (1991). “Antiguos diccionarios plurilingües del español”. Actas del ler Coloquio Internacional de Traductología, Lépinette et al. (ed.), Valencia, Universidad, 7-14.

BARSANTI Vigo, M. J. (2004). "Estudio crítico de las ediciones del Quijote de Ludwig Tieck en lengua alemana". Cervantes y el IV Centenario del Quijote (= Anuario de Estudios Cervantinos I), E. Urbina y J. G. Maestro (dirs.), Pontevedra, Mirabel Editorial, 79-89.

Breva Claramonte, M. (1994). La didáctica de las lenguas en el Renacimiento. Juan Luis Vives y Pedro Simón Abril. Con selección de textos, Bilbao, Universidad de Deusto.

ClaEs, F. (1977). Bibliographisches Verzeichnis der deutschen Vokabulare und Wörterbücher bis 1600, Hildesheim, G. Olms.

CORvo SANCHEZ, M. J. (2007a). Los libros de lenguas de Juan Ángel de Zumaran. La obra de un maestro e intérprete de lenguas español entre los alemanes del siglo XVII, Fráncfort del M., P. Lang (SABEST 12).

CORvo SANCHEZ, M. J. (2007b). "Repertorios lexicográficos en lenguas modernas en los siglos XV y XVI: estudio e ilustración”. Historia de la lexicografía española (= Anexos de Revista de Lexicografía 7), M. Campos Souto et al. (eds.), La Coruña, Universidade da Coruña, Servizo de Publicacións, 39-45.

Corvo SAnchez, M. J. (2007c). "Traducir para aprender con el alemán: Breve ilustración histórica de sus comienzos". Puente entre dos mundos: Últimas tendencias en la 
investigación traductológica alemán-español, B. Santana et al. (eds.), Salamanca, Universidad de Salamanca (Aquilafuente 118), 96-105.

DAHMEN, W. (ed.) (1991). Zur Geschichte der Grammatiken romanischer Sprachen, Tubinga, G. Narr.

Fuentes MorÁn, M. T. (2000). “La lexicografía bilingüe español-alemán”. Cinco siglos de lexicografía del español. IV Seminario de Lexicografía Hispánica. Jaén, 17 al 19 de noviembre de 1999, I. Ahumada (ed.), Jaén, Universidad de Jaén, 381-394.

GallinA, A. (1959). Contributi alla storia della lexicografía italo-spagnola dei secoli XVI e XVII, Florencia, L. S. Olschki.

HAENSCH, G. (1991). "Die mehrsprachigen Wörterbücher und ihre Probleme". Wörterbücher, Dictionaries, Dictionnaires, F. J. Hausmann, O. Reichmann y H. E. Wiegand (eds.), Berlín / Nueva York, W. de Gruyter, t. III, 2909-2938.

Hausmann, F. J. (1984). "Der Diccionario muy copioso des Nicolás Mez (1670). Ein frühes spanisch-deutsches Wörterbuch”. Navicula Tübingensis. Studia in honorem Antonii Tovar. Festschrift zum 70. Geburtstag von Antonio Tovar, F. J. Oroz Arizcuren (ed.), Tubinga, G. Narr, 167-171.

Hausmann, F. J., M. COP (1985). "Short History of English-German Lexicography". Symposium on Lexicography, K. Hylolgaard-Jensen y A. Zettersten (eds.), Tubinga, M. Niemeyer (Lexicographica. Series Maior 5), t. II, 183-197.

Hausmann, F. J. (1991). "Die zweisprachige Lexikographie Spanisch-Deutsch, DeutschSpanisch”. Wörterbücher, Dictionaries, Dictionnaires, F. J. Hausmann, O. Reichmann y H. E. Wiegand (eds.), Berlín / Nueva York, W. de Gruyter, t. III, 2987-2991.

HÜFFER, H. J. (1959). “Deutsch-Spanische Beziehungen unter Kaiser Karl V.”. Spanische Forschungen der Görres Gesellschaft: Gesammelte Aufsätze zur Kulturgeschichte Spaniens, t. 14, 183-193.

JURETSCHKE, H. (1975). "La recepción de la cultura y ciencia alemana en España durante la época romántica”. Estudios Románicos, Valladolid, Casa-Museo Zorrilla, 63-120.

KRAUS, W. et al. (1984). Das wissenschaftliche Werk, Berlín, W. de Gruyter.

MARÍN, R. (1992). "Los diccionarios bilingües español/alemán, alemán/español y los usuarios a los que se dirigen". Filología Alemana y Didáctica del Alemán. Materiales de V Simposio de la Sociedad Española de Profesores de Alemán [...], Valladolid, 6-10 de noviembre de 1989, A. Regales Serna (ed.), Valladolid, Secretariado de Publicaciones Universidad de Valladolid, 165-180.

MARIZZI, B. (2001). Manuales de lengua alemana de dos siglos. Exposición de libros de textos con ocasión de los 156 años de alemán en la enseñanza pública, I.E.S. San Isidro, Madrid, 28 de septiembre - 13 de octubre de 2001, Madrid, Asociación Española de Germanistas.

MESSNER, D. (ed.) (1999). Diccionario muy copioso de la lengua española, y alemana (1670). Gramatica, o Instruccion española y alemana (1666). Edición facsímil con un estudio preliminar de la obra de Nicolas Mez de Braidenbach, Salzburgo, Institut für Romanistik der Universität Salzburg (Biblioteca Hispano-Lusa XIV). 
Muñoz y Manzano, C., Conde de la Viñaza (1893). Biblioteca histórica de la filología castellana, Madrid, M. Tello. Reimpresión en 1978, Madrid, Atlas, 3 vols.

NeUmAnN-HolzSchuH, I. (1991). "Spanische Grammatiken in Detuschland. Ein Beitrag zur spanischen Grammatikographie des 17. und 18. Jahrhunderts". Zur Geschichte der Grammatiken romanischer Sprachen. Romanistisches Kolloquium IV, W. Dahmn et al. (eds.), Tubinga, Narr, 257-283.

NIEDEREHE, H. J. (1994). Bibliografía cronológica de la lingüística, la gramática y la lexicografía del español (BICRES). Desde los principios hasta el año 1600, Ámsterdam / Filadelfia, J. Benjamins (Studies in the History of the Language Sciences 76).

NiEDEREHE, H. J. (1999). Bibliografía cronológica de la lingüística, la gramática y la lexicografía del español (BICRES II). Desde el año 1601 hasta el año 1700, Ámsterdam / Filadelfia, J. Benjamins (Studies in the History of the Language Sciences 91).

NIEDEREHE, H. J. Bibliografía cronológica de la lingüística, la gramática y la lexicografía del español (BICRES III). Desde el año 1701 hasta el año 1800, Ámsterdam / Filadelfia, J. Benjamins (Studies in the History of the Language Sciences 108).

PALAU Y DULCET, A. (1948-1977, 2a ed.). Manual del librero hispano-americano. Bibliografía general española e hispano-americana desde a invención de la imprenta hasta nuestros tiempos, Barcelona, A. Palau Dulcet.

RUBió BALAGUER, J. (1962). "Integración de los impresores alemanes en la vida social y económica de Cataluña y Valencia en los siglos XV-XVI". Spanische Forschungen der Görres Gesellschaft: Gesammelte Aufsätze zur Kulturgeschichte Spaniens, t. 20, 103122.

SCHLIPF, W. (1956-1957). "Einige Bemerkungen zur Entwicklungsgeschichte des spanischen Wörterbuchs in Deutschland". Boletín de Filología 9, 189-234.

SCHLIPF, W. (1958). "Einige Bemerkungen zur Entwicklungsgeschichte des spanischen Wörterbuchs in Deutschland (Continuación)”. Boletín de Filología 10, 303-401.

WIPPICH-ROHÁČKOVÁ, K. (2000). Der Spannisch Liebende Hochdeutscher. Spanischgrammatiken in Deutschland im 17. und frühen 18. Jahrhundert, Hamburgo, H. Buske.

\section{Fuentes en la Red citadas:}

Allgemeine Literatur-Zeitung, seit 1785 bis 1849. Universidad de Jena, 21-04-2008, http://zs.thulb.uni-jena.de/receive/jportal_jparticle_00014680 y http://zs.thulb.uni-jena.de/receive/jportal_jparticle_00019762.

Pierer's Universal-Lexicon, 07-05-2008, http://www.zeno.org/Pierer-1857/A/CervantesSaav\%C4\%93dra.

M José Corvo Sánchez

mcorvo@uvigo.es

Universidad de Vigo 